\title{
Reflexões da prática docente por meio da pesquisa-ação: a Educação Matemática nos anos iniciais do Ensino Fundamental
}

\section{Reflections on teaching practice by the action research: Mathematics Education in the early years of Elementary Education}

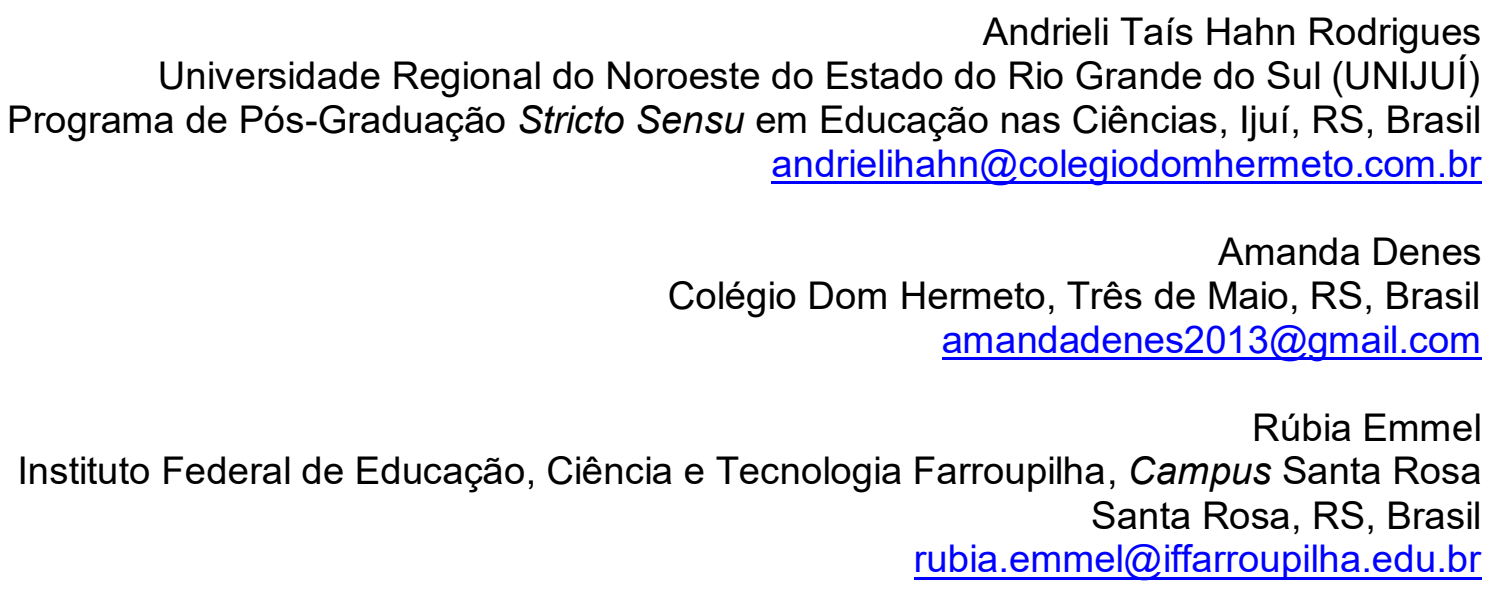

\begin{tabular}{l}
\hline Informações do Artigo \\
\hline cc) (7) \&
\end{tabular}

Histórico do Artigo

Submissão: 20 de março de 2018.

Aceite: 23 de maio de 2018.

Palavras-chave

Educação Matemática

Pesquisa-Ação

Anos Iniciais

\begin{abstract}
Resumo
Esta pesquisa teve o objetivo de compreender o ensino de Matemática nos anos iniciais em uma Escola Municipal de Ensino Fundamental. Utilizou-se como metodologia a pesquisa-ação, que permitiu investigar as metodologias de ensino utilizadas pelos professores, possibilitando posteriormente, uma prática com a participação dos alunos de uma turma do segundo ano do Ensino Fundamental. Por meio da pesquisa-ação refletiu-se sobre a prática docente, seguindo as etapas de observação, planejamento e intervenção do ensino de Matemática. A análise dos resultados evidenciou que nos anos iniciais se requer a utilização do lúdico, ambientes diferenciados e equipados com materiais concretos, qualificando os processos de ensino e de aprendizagem em Educação Matemática. Portanto, esta pesquisa possibilitou uma compreensão maior sobre o ensino da Matemática nos anos iniciais do Ensino Fundamental, contribuindo para a aprendizagem dos alunos.
\end{abstract}

\section{Keywords}

Mathematics Education

Action Research

Early Years

\section{Abstract}

This research had as objective to understand the teaching of Mathematics in the early years in a Municipal School of Elementary Education. It was used as methodology the action research, that allowed to investigate the teaching methodologies used by the teachers, opportunizing posteriorly a practice with the participation of the students of a second year class. The action research allowed reflections on the teaching practice, following the stages of observation, planning and intervention of the teaching of Mathematics. The analysis of the results showed that in the early years it is required the use of playful, differentiated environments and equipped with concrete materials, qualifying the processes of teaching and learning in Mathematics Education. Therefore, this research made possible a greater understanding about the teaching of Mathematics in the early years of Elementary School, contributing to the students' learning. 


\section{Introdução}

A Educação Matemática constitui-se em um dos desafios ao exercício profissional de professores/as nos anos iniciais, considerando a formação de professores, o ensino e a aprendizagem da Matemática. Os estudos de Nacarato et al. (2009) mostram que os cursos de formação inicial em Pedagogia ainda são deficitários na formação Matemática. Partindo destes cenários, nesta investigação foram realizadas leituras de referenciais teóricos que vêm contribuindo para o ensino da Matemática: Lorenzato (2010); Fiorentini (1994); Smole et al. (2007). Por meio das leituras e reflexões destes autores foi possível perceber que o ensino da Matemática nos anos iniciais é de extrema importância, pois nesta etapa as crianças adentram no mundo das letras, números, domínio das quatro operações básicas, noções de espaço, entre outros. Para isso, o professor pode proporcionar momentos de aprendizagem que envolvam diferentes metodologias (uso de material concreto, jogos, dinâmicas diversificadas, desafios).

Este estudo tem o objetivo de compreender o ensino da Matemática nos anos iniciais a partir de uma Escola Municipal de Ensino Fundamental. Realizamos uma investigação com o intuito de perceber os modos de ensinar Matemática nos anos iniciais e como os alunos compreendem/aprendem a Matemática a partir das metodologias utilizadas pelos professores.

Para melhor compreender estas ideias propomos a análise da Educação Matemática no contexto da prática com alunos dos anos iniciais. Este artigo divide-se em seis subtítulos principais nos quais apresentamos os aspectos introdutórios da pesquisa, o percurso metodológico, o referencial teórico sobre o ensino e a aprendizagem da Matemática e os aspectos da formação de professores para a Matemática nos anos iniciais. Posteriormente, apresentamos o contexto de análise, a descrição, o planejamento da análise de intervenção, e as considerações finais.

\section{Metodologia: Constituindo uma Pesquisa-Ação no Ensino da Matemática nos Anos Iniciais}

Apresentamos a metodologia da pesquisa em cinco subtítulos que descrevem os percursos metodológicos incluindo a natureza e o tipo de investigação, contexto do estudo, os instrumentos de coleta de dados, e os métodos de análise dos dados.

\subsection{Natureza da Investigação}

Esta pesquisa em Educação Matemática é de natureza qualitativa. Conforme Lüdke e André (1986, p. 11), “[...] a pesquisa qualitativa supõe o contato direto e prolongado do pesquisador com o ambiente e a situação que está sendo investigada, via de regra através do trabalho de intensivo de campo". Nesta abordagem, "[...] preocupação com o processo é muito 
maior do que com o produto" (LÜDKE; ANDRÉ, 1986, p. 12); e as autoras ainda complementam que a complexidade do cotidiano escolar é sistematicamente retratada nas pesquisas qualitativas.

\subsection{Tipo de Investigação}

Esta pesquisa-ação em Educação Matemática investigou as metodologias exploradas nas aulas de Matemática do Ensino Fundamental e, posteriormente, foi planejada e desenvolvida uma intervenção pedagógica em uma turma previamente investigada.

A pesquisa-ação, segundo Franco (2005), é a condição para um mergulho crítico na práxis de um grupo a ser estudado, no qual percebem-se as expectativas, o oculto, o que norteiam as práticas, que enfatizam o coletivo e que podem assumir o caráter crítico. Nesta pesquisa-ação buscou-se refletir sobre o ensino da Matemática, bem como sobre as metodologias de ensino utilizadas pelos professores, possibilitando o envolvimento e a participação dos sujeitos da pesquisa.

Podemos pensar esta intervenção pela proposta do trinômio pesquisa-formação-ação que é descrito por Alarcão (2011, p. 52), na figura de uma espiral, desenvolvida por movimentos cíclicos de planificação, ação, observação e reflexão. No contexto da pesquisa-ação, realizamos anterior à intervenção, as observações da realidade, o planejamento das ações, as ações de intervenção e, neste movimento, a reflexão. Alarcão (2011), ao analisar o processo reflexivo pelo viés de Schön (2000), que propõe os componentes da reflexão na ação e sobre a ação, acresce a reflexão para a ação, aspecto importante para a pesquisa-ação, configurando um olhar que se projeta, prospectivamente, e avança cada vez mais nos processos formativos.

\subsection{Contexto do Estudo}

A pesquisa realizou-se em uma escola da rede municipal (M1), em uma turma de segundo ano, nos anos iniciais do Ensino Fundamental. Primeiramente, foi conversado com a direção de uma escola estadual com o intuito de pesquisar e conhecer a realidade Matemática dos anos iniciais do Ensino Fundamental, mas percebemos a resistência em possibilitar um espaço para a pesquisa, o que acarretou em uma nova busca por uma instituição. Logo, encontramos uma escola que permitiu adentrarmos no ambiente escolar. Fomos recebidas pela direção da escola, a qual mostrou-se interessada em ouvir as propostas para a pesquisa, coleta de dados e posterior intervenção.

Por meio do diálogo estabelecido com a direção, foi possível conhecer a organização, as rotinas, a estruturação do quadro de professores e um pouco do cotidiano escolar. Desta forma, percebemos a preocupação em ofertar momentos para o planejamento dos professores, tendo assim, aulas planejadas, pensadas com finalidades de ficar aquém das dificuldades encontradas em sala de aula, bem como em abranger os conteúdos de forma interdisciplinar. 


\subsection{Instrumentos de Coleta de Dados}

Entre os instrumentos de coleta de dados, em um primeiro momento, foi utilizada a observação das aulas, em específico os momentos e períodos dedicados ao ensino da Matemática. A partir da interação dos pesquisadores com os sujeitos pesquisadores-ativos foram observadas a participação no processo de ensino e as interações promovidas em suas aprendizagens, se há a possibilidade de expressar as dúvidas, opiniões, sugestões e se estas são aceitas pelos profissionais da educação.

Como instrumento de coleta de dados foram realizadas entrevistas com a finalidade de conhecer as realidades dos professores que atuam nos anos iniciais $\left(1^{\circ}, 2^{\circ}\right.$ e $3^{\circ}$ anos), suas perspectivas, angústias, formações e metodologias. Ressaltamos que, neste escrito, não apresentamos as análises da entrevista, mas este também serviu de base para refletirmos sobre o ensino da Matemática.

Posteriormente, foram realizados os planejamentos das atividades de intervenção, por meio de conversas informais com a professora da turma, do estudo do que ocorreu nas observações, e de leituras sugeridas pela professora a partir do plano de estudos da turma.

Ainda como instrumento, tivemos a ação e execução das atividades planejadas. A partir da intervenção, enquanto pesquisadoras-ativas, nos desafiamos a promover reflexões sobre as práticas que desenvolvemos.

\subsection{Metodologia de Análise dos Dados}

A análise dos dados foi estruturada pela análise descritiva e interpretativa, considerando o tratamento qualitativo interpretativo desenvolvido nos estudos sobre a pesquisa-ação de Thiollent (1986). Para este autor, na pesquisa-ação a análise de dados exige: "[...] todo um trabalho de investigação e de interpretação dentro da problemática adotada e levando em conta a pesquisa com elementos 'explicativos'” (THIOLLENT, 1986, p. 71). Considerando esses aspectos, trata-se de uma análise que "[...] poderá gerar reações e contribuir para a dinâmica da tomada de consciência e, eventualmente, sugerir o início de mais um ciclo de ação e de investigação" (THIOLLENT, 1986, p. 71).

Pela análise foi possível refletir sobre as metodologias e os planejamentos utilizados pelos professores. Dessa forma, realizamos os planejamentos e a intervenção com o intuito de compreendermos e refletirmos, pela pesquisa-ação, o ensino da Matemática nos anos iniciais.

\section{Referencial Teórico}

Partimos de leituras e embasamentos teóricos e apresentamos o referencial teórico a partir de duas seções de estudos: a primeira aborda os processos de ensino de Matemática para que haja aprendizagem desta disciplina nos anos inicias; a segunda traz reflexões teóricas sobre a formação de professores para a Matemática nos anos iniciais. 


\subsection{Ensino e Aprendizagem da Matemática nos Anos Iniciais}

As escolas podem buscar recursos e metodologias facilitadoras para a aprendizagem de seus alunos. Conforme Lorenzato (2010, p. 5):

[...] não faltam argumentos favoráveis para que as escolas possuam objetos e imagens a serem utilizados nas aulas, como facilitadores da aprendizagem. Justamente por isso, decorre uma inescapável necessidade de as escolas possuírem laboratórios de ensino dotados de materiais didáticos de diferentes tipos.

Entre as propostas para o ensino da Matemática nos anos inicias estão os investimentos em recursos como para a construção dos Laboratórios de Ensino da Matemática (LEM):

Se lembrarmos que mais importante que ter acesso aos materiais é saber utilizálos corretamente, então não há argumentos que justifique a ausência de LEM nas instituições responsáveis pela formação de professores, pois é nelas que os professores devem aprender a utilizar os materiais de ensino; é inconcebível um bom curso de formação de professores de Matemática sem LEM. (LORENZATO, 2010, p. 10).

Acreditamos que com os laboratórios de ensino as escolas podem estar sensíveis às necessidades de aprendizagem de seus alunos, identificando as dificuldades dos mesmos. Para tanto é necessário estar inteirado dos direitos que possuem perante as políticas públicas, procurando meios para receber materiais que auxiliem na produção de conhecimentos significativos. Como já salientava Lorenzato (2010), mesmo que o Laboratório de Ensino da Matemática tenha condições desfavoráveis, há maneiras de tornar o trabalho do professor significativo e gratificante, de forma que o aluno tenha uma aprendizagem compreensível e agradável, inclusive integrando o ensino da Matemática ao ensino das demais áreas do conhecimento, em uma perspectiva de trabalho interdisciplinar.

O tema "Matemática nos anos iniciais" pressupõe uma análise de documentos oficiais, verificando os elementos que julgam ser importantes para uma educação/aprendizagem de qualidade. $\mathrm{Na}$ observação da realidade, por vezes, estes elementos não são postos em prática, o que acarreta em desinteresse, desmotivação por parte dos alunos, pois a Matemática torna-se algo abstrato que não faz sentido com o real, tornando-se assim chata, desnecessária no cotidiano dos alunos.

Neste sentido, ao estudarmos as metodologias para o ensino da Matemática nos anos iniciais, no contexto das práticas docentes, passamos a refletir sobre estas, e propor um ensino de Matemática mais contextualizado e que partem de resoluções de problemas que envolvem o concreto, o cotidiano $\mathrm{e}$ as realidades dos alunos. Que as práticas docentes sejam contextualizadas e reconheçam os conhecimentos das crianças, traduzindo-se em alfabetização Matemática.

Refletimos com Fernández (2001, p. 31): “Embora os professores precisem possuir informação, sua função principal não é transmiti-la, mas propiciar ferramentas e espaço adequado (lúdico) onde seja possível a construção do conhecimento". 
Ao refletir sobre as metodologias utilizadas pelos professores, compreendemos a importância de novas técnicas e recursos no planejamento das aulas, tornando-as mais atrativas, criativas, dinâmicas, lúdicas, promovendo uma aprendizagem significativa. Conforme Soares (2009, p. 53):

A aprendizagem significativa [...] é definida como a aprendizagem que ocorre quando as ideias novas estão ligadas a informações ou conceitos já existentes na estrutura cognitiva do indivíduo. Ou seja, a aprendizagem significativa só ocorrerá quando uma nova informação relaciona-se, de maneira substantiva (não literal) e não arbitrária, a um aspecto da base de formação conceitual do educando.

Corroborando com Soares (2009), uma aprendizagem significativa ocorre quando a criança consegue ressignificar os conhecimentos já existentes e formular os novos. Nesta perspectiva Soares (2009, p. 53) afirma que:

A aprendizagem significativa caracteriza-se pela interação de uma informação a um aspecto relevante da estrutura cognitiva do sujeito, não a qualquer aspecto. Uma informação é aprendida de forma significativa, quando se relaciona a outras ideias, conceitos ou proposições relevantes e inclusivos, que estejam claros e disponíveis na mente do indivíduo e funcionem como âncoras.

Neste contexto percebemos, a partir de Soares (2009), a importância de estabelecer nas aulas de Matemática uma aprendizagem significativa com os alunos, pois esta é o contrário da memorização ou mecanização; e possibilita que consigam resolver problemas cotidianos e contextuais com mais facilidade.

\subsection{Formação de Professores de Matemática para os Anos Iniciais}

A formação de professores para o ensino de Matemática tem como objetivo refletir sobre a prática, sabendo e utilizando os materiais necessários e as diferentes metodologias de ensino que podem ser utilizadas nas aulas, auxiliando assim, na mediação da aprendizagem dos alunos, aliando as novas tecnologias a favor da produção de novos conhecimentos.

Emergem inquietações quanto ao ensino da Matemática, no contexto dos anos iniciais, considerando que o Pedagogo é o professor da Educação Básica que terá a formação e a habilitação para atuar nesta etapa escolar. Nesta perspectiva, conforme Fiorentini (1995, p. 5):

O professor que acredita que o aluno aprende Matemática através da memorização de fatos, regras ou princípios transmitidos pelo professor ou pela repetição exaustiva de exercícios, também terá uma prática diferenciada daquele que entende que o aluno aprende construindo os conceitos a partir de ações reflexivas sobre materiais e atividades, ou a partir de situações problema e problematizações do saber matemático.

Sabendo das dificuldades encontradas na educação brasileira, sendo uma delas os ambientes e laboratórios de Matemática equipados com os materiais adequados para a aplicação das aulas, outro aspecto que é frequente nas escolas são os professores que ainda não possuem a habilitação em Curso Superior de Licenciatura para atuar nos anos iniciais do Ensino Fundamental. 
Nesta perspectiva é necessário refletir sobre o ser professor da atualidade, que segundo Fiorentini (1994, p. 586),

Emerge nesse processo, um tipo de profissionalidade docente que pode ser qualificada como interativa, reflexiva, investigativa e, portanto, deliberativa e que consiste no desenvolvimento da capacidade dos profissionais do ensino trabalharem colaborativamente num ambiente de diálogo e interação, onde discutem, analisam, refletem e investigam sobre seu trabalho, buscando compreendê-lo e transformá-lo.

Corroborando com Fiorentini (1994), refletimos sobre o ser professor da atualidade, o qual deve ter traços de um profissional reflexivo, investigativo, criativo, sensível, interativo. Nesta pesquisa-ação acreditamos que este desenvolvimento dos professores é possível.

\section{Contexto de Análise: Reflexões a partir das Observações}

Realizamos a observação da aula de Matemática em uma turma do segundo ano, do primeiro ciclo nos anos iniciais do Ensino Fundamental. No dia da observação, o tempo estava abafado com pouco vento e todos os alunos estavam dentro da sala de aula, que é pequena e com pouca circulação de vento. A professora havia organizado a sala em fileiras de quatro alunos em cada, eles estavam bastante agitados, pois haviam voltado a pouco do intervalo.

Foi marcada a observação para uma quarta-feira, mas houve um imprevisto de modo que remarcamos para o dia seguinte. Em uma tarde de quinta-feira, ensolarada, nos foi oportunizado a observação das aulas de Matemática na turma do segundo ano composta por vinte alunos, sendo 9 meninas e 11 meninos. A professora havia planejado a confecção de um gráfico a partir das lendas do folclore; cada criança deveria votar qual mais gostava e posteriormente registrar o gráfico no caderno. A professora utilizou o papel pardo para a confecção do cartaz, imagens das lendas e para marcar o voto das crianças um quadrado pequeno colorido. A atividade teve a duração de quarenta minutos.

Em uma conversa informal, a professora relatou: "Que pena que não vieram ontem, pois havia planejado uma atividade legal, e as crianças estavam entusiasmadas para a realização". Percebemos que talvez a professora havia planejado algo "diferente" da rotina em função de nossa observação.

Após a confecção do gráfico, ela apenas contou quantos votos cada lenda teve, e não buscou a interpretação, que poderia ter sido realizada por meio de questionamentos como: "Qual lenda teve empate?", "Qual lenda teve menos votos?", "Por que foi escolhida a lenda da lara como ganhadora e não a do Saci-Pererê". A atividade planejada foi atrativa para os alunos, uma vez que era algo diferente da rotina, porém, poderia ter sido mais explorada e problematizada pela professora, pois poderia ter utilizado várias questões de interpretação, bem como o registro em papel quadriculado ou no caderno de modo que estes viessem a fixar a interpretação dos gráficos.

Neste contexto, relembramos os estudos das tendências de Fiorentini (1994) e percebemos, nas observações que a professora contemplou, traços da tendência construtivista, 
pois esta trabalha com estruturas abstratas, priorizando o processo de construção e não os resultados, bem como a tendência socioetnoculturalista, levando em consideração os conhecimentos prévios dos alunos e que a Matemática é um conhecimento prático e dinâmico. Desta forma, percebemos que a professora, após dezoito anos atuando nos anos iniciais, adotou seus próprios métodos, buscando atender as necessidades que percebe das turmas. Porém, nas observações os alunos não manifestaram dúvidas ou questionamentos, pois a professora não dinamizou as atividades e utilizou apenas o quadro para explicação e anotação das atividades e o registro dos alunos se deu no caderno.

Ressaltamos Alarcão (2011, p. 50): "Queremos que os professores sejam seres pensantes, intelectuais, capazes de gerir a sua ação profissional. Queremos também que a escola se questione a si própria, como motor do seu desenvolvimento institucional". Corroborando com Alarcão (2011), acreditamos que os professores podem assumir a função de professores reflexivos, repensando suas metodologias e didática diariamente, para tornar-se, assim, um profissional criativo, inovador e não apenas um transmissor de conhecimento.

\subsection{O Contexto da Intervenção e Planejamento das Ações de Intervenção}

Ao observar a turma pensamos na proposta de intervenção, partindo de todo o contexto já analisado e exposto nos itens anteriores, foi possível desenvolver uma ação para uma Educação Matemática que buscou contribuir com o trabalho já realizado pela professora. Foram desenvolvidas ações com ênfase na ludicidade, por meio de jogos que estimulassem o desenvolvimento da cooperação, trabalho em grupo, percepção, raciocínio, destreza, noção de espaço, coordenação motora, entre outros.

Planejamos as atividades, duas charadas retiradas do livro: "Poemas Problemas" de Bueno (2012), o qual traz atividades de Matemática de maneira diversificada. Posteriormente, foi confeccionado o boliche com garrafas pet de $500 \mathrm{ml}$, em que cada garrafa continha um elemento diferente dentro (arroz, feijão, pipoca, e.v.a., farinha, lentilha), e rotuladas com um número de 1 a 12.

A intervenção ocorreu na escola M1, com o segundo ano do Ensino Fundamental, dia 14 de setembro de 2016, no turno da tarde; o dia estava ensolarado e quente, o que oportunizou o desenvolvimento das atividades em espaço mais amplo, no pátio da escola. Ao chegar na escola fomos recepcionadas pela diretora que nos encaminhou até a sala de aula da turma, as crianças estavam sentadas em fila, nos aguardando para realizar as atividades de Matemática. Neste dia, estávamos ansiosas, cheias de expectativas perante a realização das atividades, recepção dos alunos e professora, principalmente se os alunos iam gostar das atividades propostas, se teriam dificuldades, se iam participar ou não. Lembrando que a intervenção foi planejada de acordo com a realidade da turma, respeitando o nível de escolarização, possibilitando atividades lúdicas e significativas para a aprendizagem. 
Ao adentrar à sala de aula fomos recepcionadas pelas crianças com "Boa tarde, sejam bem-vindas a nossa escola!". Perguntamos se lembravam quem éramos, responderam que "Sim!". As atividades de intervenção tiveram a duração maior que o planejado, duraram uma hora e meia.

\subsubsection{Descrição das Atividades de Intervenção: do Planejamento à Ação}

Após conversas informais com os alunos sobre quem éramos, explicamos como iria ocorrer a intervenção; solicitamos que formassem quatro grupos de cinco crianças cada, pois eram vinte crianças. Foi distribuído um número de um a cinco para cada criança, esse número era respectivo ao grupo. Assim que os grupos foram organizados iniciamos as atividades de resolução dos problemas: era grupo que faltava componentes, classes que não passavam nos espaços, evidenciando as dificuldades dos alunos em movimentar-se dentro da sala de aula e de organizar-se em dinâmicas que oportunizem estudos em grupos. O que nos levou a questionar se realmente a professora realiza atividades em grupos que exijam movimentação e deslocamento como havia relatado na entrevista.

Depois dos grupos organizados, explicamos como iria ocorrer a intervenção. Primeiramente, na sala de aula, foram feitas as duas charadas Matemáticas; a primeira $(\mathrm{CH} 1)$ era a seguinte: "No aquário que comprei há dois peixes vermelhinhos, um laranja que é o rei, e mais nove amarelinhos. Ao todo, nadando juntos, quantos são os peixinhos?"; a segunda $(\mathrm{CH} 2)$ era "O Teo tem um gato, que se chama Cissaninho. O menino colocou em seu prato 8 cenouras e 1 peixinho. Cissano comeu metade das cenouras, e o peixe inteirinho. Você sabe quanto sobrou em seu pratinho?"

As charadas envolviam a resolução de problemas matemáticos que exigiram dos alunos: leitura, interpretação, lógica, adição, conjuntos, metade, inteiro, subtração. As charadas foram escritas no quadro branco uma por vez, e cada grupo fez o registro das resoluções em uma folha de ofício; posteriormente foi realizada a correção no grande grupo e verificado se os grupos acertaram ou não as charadas de forma individual.

O boliche foi realizado na área coberta da escola, encaminharam-se dois grupos por vez para jogar. Cada jogador teve a chance de arremessar a bola e pontuar para seu grupo. Após todos terem jogado, encaminharam-se para a sala de aula, e cada grupo fez a soma da pontuação; foi construída uma tabela para os alunos anotarem os pontos do jogo de Boliche e realizar as adições. Durante o jogo do boliche, percebemos um grande envolvimento pelos alunos, respeitando as regras do jogo, uma ordem a ser seguida para o bom desenvolvimento da atividade. Os alunos não encararam como atividade de competição e sim estavam desfrutando/participando de um jogo que consideram legal que, ligado à Matemática, tornou-se agradável e de muitas aprendizagens. Após a realização das atividades (charadas e boliche) foi realizada o somatório dos pontos, para enfim declarar as ordens de classificações e identificar o grupo campeão. 


\section{Análise da Intervenção}

$\mathrm{Na}$ organização dos grupos percebeu-se que os alunos demonstraram dificuldade em organizar-se no espaço da sala de aula, sendo esta pequena e com pouca ventilação, o que nos levou a refletir se realmente a P2 utilizava a metodologia de movimentação e trabalho em grupos dentro da sala de aula, ou se ela apenas escreve no quadro e eles registram. Neste contexto, segundo a Resolução $n^{\circ}$ 7, de 2010, em seu Artigo 30:

Os três anos iniciais do Ensino Fundamental devem assegurar: aprendizagens básicas, imprescindíveis para o prosseguimento dos estudos. $\S 2^{\circ}$ Considerando as características de desenvolvimento dos alunos, cabe aos professores adotar formas de trabalho que proporcionem maior mobilidade das crianças nas salas de aula [...] a utilizar materiais que ofereçam oportunidades de raciocinar, manuseando-os e explorando as suas características e propriedades. (BRASIL, 2010).

Nesta perspectiva, os professores precisam planejar aulas que possibilitem a mobilidade dos alunos como traz a Resolução, promovendo aulas diferenciadas, com atividades em grupos que exijam manuseio de materiais diversificados e que instiguem a noção de espaço, tempo, raciocínio e organização. Ao planejar, as professores podem levar em consideração também os ambientes externos que a escola disponibiliza. Nesta dinâmica é que planejamos atividades que abrangessem a sala de aula, bem como o pátio da escola.

Em conversas informais com a professora da turma, antes do planejamento da intervenção, ela relatou que a maioria das crianças não tinham dificuldades, eram apenas dois ou três alunos que demonstravam dificuldades. Nesta perspectiva, para as atividades sala de aula, planejou-se as charadas $(\mathrm{CH} 1, \mathrm{CH} 2)$. A CH1 exigia que elaborassem uma conta de adição, a qual considerávamos fácil; porém, no decorrer da resolução surgiram muitas dúvidas e questionamentos, em que tivemos que parar e auxiliar os alunos na montagem da conta, explicando os conceitos de dezena e de unidade. A professora, acompanhou o andamento da intervenção e auxiliou nas explicações para os grupos. Isso nos levou a refletir sobre a importância de instigar o desempenho dos alunos na resolução de problemas. Segundo Smole et al. $(2007$, p. 14$)$,

Nossa proposta de utilização de jogos está baseada em uma perspectiva de resolução de problemas, o que, em nossa concepção, permite uma forma de organizar o ensino envolvendo mais que aspectos puramente metodológicos, pois inclui toda uma postura frente ao que é ensinar e, consequentemente, ao que significa aprender. Daí a escolha do termo, cujo significado corresponde a ampliar a conceituação de resolução de problemas como simples metodologia ou conjunto de orientações didáticas.

Nesta perspectiva, a professora poderia inserir metodologias que possibilitem reavaliar os conhecimentos dos alunos e sua didática; desta forma, conseguirá abranger mais as dificuldades encontradas pelos alunos, tornando os processos de ensino e de aprendizagem da Matemática agradáveis. 
A $\mathrm{CH} 2$, abrangeu a composição de conjuntos e exigia a montagem de duas contas, interpretação e raciocínio lógico, o que foi de difícil resolução pelos alunos, pois não compreendiam que a questão envolvia dois objetos diferentes e duas contas separadas, e novamente não conseguiram armar a conta para resolvê-la. Os que conseguiram resolver pelo raciocínio lógico sabiam o resultado, mas não conseguiam registrar na folha. Assim, o restante da turma solicitou auxílio, o que exigiu bastante tempo para as explicações. Nesta perspectiva, Chica (2001, p. 153) reforça que:

[...] é preciso estimular a capacidade inventiva e questionadora dos alunos, desenvolvendo na sala um clima de interação e respeito, onde se possa fazer matemática através da possibilidade de questionar, levantar hipóteses, comunicar idéias, estabelecer relações e aplicar conceitos.

Corroborando com as ideias de Chica (2001), os alunos ao serem submetidos a experiências/desafios novos, demonstraram dificuldade em relacionar a nova maneira dos problemas $(\mathrm{CH} 1, \mathrm{CH} 2)$, com os conteúdos que estudam diariamente. Desta forma, a Matemática pode ser ensinada de modo que instigue os alunos à resolução de diferentes problemas, e apresente-os de formas diversificadas.

Após a realização das charadas, dois grupos foram encaminhados para o pátio da escola para a realização do boliche, e os outros ficaram na sala terminando as atividades. Com o jogo do boliche, notamos como os alunos gostam de realizar atividades diferenciadas em outros espaços da escola. A maioria expressava o desejo de que "gostariam de jogar novamente", demostrando euforia e entusiasmo com o jogo. Com a finalização do jogo, notamos que os alunos gostaram, principalmente por estarmos em outro ambiente que não fosse a sala de aula, e que é possível tornar a Matemática prazerosa por meio de atividades diferenciadas. Ao nos despedir, os alunos foram calorosos, agradeceram e alguns chegaram a nos abraçar. A professora da turma também agradeceu e nos relatou que a intervenção contribuiu para perceber as dificuldades dos alunos perante a Matemática. Percebemos o quanto foi importante proporcionar atividades lúdicas como jogos para o ensino da Matemática, principalmente atividades como o jogo de boliche que tem caráter interdisciplinar, estimulando o desenvolvimento dos alunos em vários aspectos, possibilitando, também, o movimento e a corporeidade na Educação Matemática. Segundo Borin (1996, p. 9), o jogo nas aulas de Matemática possibilita

[...] diminuir bloqueios apresentados por muitos de nossos alunos que temem a Matemática e sentem-se incapacitados para aprendê-la. Dentro da situação de jogo, onde é impossível uma atitude passiva e a motivação é grande, notamos que, ao mesmo tempo em que estes alunos falam Matemática, apresentam também um melhor desempenho e atitudes mais positivas frente a seus processos de aprendizagem.

Corroborando com Borin (1996), sabemos que muitos alunos apresentam dificuldades na aprendizagem de conteúdos da Matemática, mas cabe aos professores planejar aulas com métodos de ensino que possibilitem aos alunos diferentes formas de resolução dos problemas, o que os instiga a aprender e não ser "temedores" da Matemática. 
Após a realização das atividades, em conversa informal com a professora, esta relatou como foi importante a intervenção, pois possibilitou perceber as dificuldades apresentadas pelos alunos, que no cotidiano escolar, durante as suas aulas, não foi possível notar; ou seja, pela pesquisa-ação, foi possível que a professora também refletisse sobre a sua prática nas aulas de Matemática. No momento em que nos possibilitou espaço para desenvolver a intervenção, também passou a ser pesquisadora, pois acreditou na nossa intervenção e por meio desta pesquisa-ação passou a perceber a turma com um olhar mais reflexivo, e até mesmo crítico sobre o ensino e as aprendizagens dos alunos. O que nos levou a refletir, a partir do observado, é que a professora, possivelmente, realiza em suas aulas de Matemática contas prontas, já armadas, em que os alunos precisam apenas resolver, o que não possibilita aos alunos pensar como fazer (interpretação) e armar estas contas (raciocínio lógico), limitando o ensino da Matemática. Neste contexto, refletimos:

[...] o ensino de Matemática prestará sua contribuição, à medida que forem exploradas metodologias que priorizem a criação de estratégias, a comprovação, a justificativa, a argumentação, o espírito crítico, e favoreçam a criatividade, o trabalho coletivo, a iniciativa pessoal e a autonomia advinda do desenvolvimento da confiança na própria capacidade de conhecer e enfrentar desafios (BRASIL, 1997, p. 31).

Desta forma, o ensino da Matemática pode priorizar a elaboração e o planejamento de atividades que possibilitem a argumentação, o pensar crítico sobre o aprendizado, promovendo a resolução de problemas, que ainda, conforme Cavalcanti (2001, p. 126):

[...] cabe ao professor planejar ações que assegurem um espaço para a elaboração individual de estratégias e momentos coletivos, ou em pequenos grupos, para que as crianças apresentem suas hipóteses e possam ouvir a opinião dos colegas a respeito de seu procedimento de resolução.

Nesta perspectiva, o ensino da Matemática pode envolver os alunos com diferentes metodologias e problemas a serem resolvidos para que, desta forma, tornem-se alunos pensantes, críticos, criativos, autônomos, questionadores e que dialoguem as suas dúvidas acarretando em uma aprendizagem significativa.

\section{Considerações Finais}

Por meio da intervenção, com atividades lúdicas, foi possível perceber, que as crianças possuem dificuldades em aprender Matemática, mesmo em elementos básicos como armar o cálculo, pois no decorrer da intervenção foi necessário explicar e relembrar como se realizava a estrutura operatória do cálculo $(\mathrm{CH} 1)$ e diferenças entre conjuntos $(\mathrm{CH} 2)$; por vezes, essas dificuldades passam despercebidas pelo professor, pois este prende sua atenção em escrever tudo no quadro e os alunos registram no caderno, tornando assim, o ensino mecânico e monótono, de modo que impossibilita as crianças a elaborar um processo de raciocínio para a resolução dos problemas/atividades. Neste contexto, foi possível perceber por meio da pesquisa- 
ação que a professora utilizava metodologias tradicionais, investindo pouco no lúdico e não proporcionando ambientes e atividades diferenciadas.

Percebemos que o ensino da Matemática pode ser melhorado por meio de inovações das metodologias, como a troca do ambiente que pode contribuir ao possibilitar às crianças um estímulo diferenciado, um novo método/jeito de "ver" a Matemática, indo além dos limites da sala de aula, possibilitando uma Educação Matemática. Neste caso, vale ser relembrado o jogo de boliche realizado na intervenção, na área externa e coberta da escola, sendo esta uma atividade com materiais reciclados em ambiente diferenciado, que envolveu o lúdico para tornar a aprendizagem significativa.

Enquanto professoras e pesquisadoras surgiram inquietações, questionamentos, e esta investigação desencadeou reflexões sobre as metodologias utilizadas para o ensino da Matemática nos anos iniciais do Ensino Fundamental.

A pesquisa-ação possibilitou uma visão da realidade de sala de aula da atualidade, o que em alguns aspectos nos deixou frustradas com as metodologias de ensino da Matemática utilizadas, sendo estas tradicionais, o oposto do que nos é instigado na formação inicial, o que nos levou a refletir sobre pontos fundamentais para este processo, como a utilização do lúdico, os materiais e os ambientes diferenciados.

Tendo em vista os aspectos observados, e as curiosidades iniciais sobre a Matemática que foram investigadas, as observações e a intervenção, percebemos que o ensino da Matemática pode estar deixando algumas lacunas nos anos iniciais, o que é um dos fatores que acarretam em futuros "temedores" da Matemática nos anos finais do Ensino Fundamental e no Ensino Médio.

Em virtude da análise apresentada e dos aspectos pesquisados, foi possível ressignificar conceitos sobre o ensino e as metodologias da Matemática, bem como sobre o ser professor em sala de aula, o que exige a reflexão das ações e das práticas, e a percepção das dificuldades dos alunos. Portanto, para que o planejamento esteja de acordo com a realidade e a aprendizagem seja significativa, levamos em consideração os conhecimentos prévios e a faixa etária dos alunos. Acreditamos que a investigação oportunizou reflexões no contexto da prática docente e permitiu ressignificar a Educação Matemática e seu ensino nos anos iniciais do Ensino Fundamental.

\section{Referências}

ALARCÃO, I. Professores reflexivos em uma escola reflexiva. São Paulo: Cortez, 2011.

BORIN, J. Jogos e Resolução de Problemas: uma estratégia para as aulas de Matemática. São Paulo: IMEUSP, 1996.

BRASIL. Ministério da Educação. Conselho Nacional de Educação. Câmara de Educação Básica. Resolução $n^{\circ}$ 7, de 14 de dezembro de 2010. Fixa Diretrizes Curriculares Nacionais para o Ensino Fundamental de 9 (nove) anos. Brasília: MEC/CNE/CEB, 2010. 
BRASIL. Ministério da Educação. Secretaria da Educação Fundamental. Parâmetros

Curriculares Nacionais: Matemática. v. 3. Brasília: MEC/SEF, 1997.

BUENO, R. Poemas Problemas. São Paulo: Editora do Brasil, 2012.

CAVALCANTI, T. C. Formas de Resolver Problemas. In: SMOLE, K. S.; DINIZ, M. I. Ler, Escrever e Resolver Problemas: habilidades básicas para aprender matemática. Porto Alegre: Artmed, 2001. p. 126-150.

CHICA, H. C. Por que formular problemas? In: SMOLE, K. S.; DINIZ, M. I. Ler, Escrever e Resolver Problemas: habilidades básicas para aprender matemática. Porto Alegre: Artmed, 2001. p. 151-173.

FERNÁNDEZ, A. O Saber em jogo: a Psicopedagogia propiciando autorias de pensamento. Porto Alegre: Artmed, 2001.

FIORENTINI, D. Alguns Modos de Ver e Conceber o Ensino da Matemática no Brasil. Zetetikê, Campinas, v. 3, n. 1, p. 1-38, 1995.

FIORENTINI, D. Rumos da Pesquisa Brasileira em Educação Matemática: o caso da produção científica em cursos de pós-graduação. 1994. 414 f. Tese (Doutorado em Educação) - Faculdade de Educação, Universidade Estadual de Campinas. Campinas, 1994.

FRANCO, M. Pedagogia da pesquisa-ação. Educação e Pesquisa, São Paulo, v. 31, n. 3, p. 483502, set./dez. 2005.

LORENZATO, S. Laboratório de ensino de Matemática e materiais didáticos manipuláveis. In:

LORENZATO, S. (Org.). O Laboratório de Ensino de Matemática na Formação de

Professores. 2. ed. Campinas: Autores Associados. 2010. p. 3-38.

LÜDKE, M.; ANDRÉ, M. E. D. A. Pesquisa em Educação: abordagens qualitativas. São Paulo: EPU, 1986.

NACARATO, A. M.; MENGALI, B. L. S.; PASSOS, C. L. B. A matemática nos anos iniciais do Ensino Fundamental: tecendo os fios do ensinar e do aprender. Belo Horizonte: Autêntica, 2009.

SCHÖN, D. Educando o Profissional Reflexivo: um novo design para o ensino e aprendizagem. Porto Alegre: Artmed, 2000.

SMOLE, K. S; DINIZ, M. I; CÂNDIDO, P. Jogos de Matemática de $1^{\circ}$ a $5^{\circ}$ Ano. Porto Alegre: Artmed, 2007.

SOARES, L. H. Aprendizagem Significativa na Educação Matemática: uma proposta para a aprendizagem de geometria básica. 2009. 137 f. Dissertação (Mestrado em Educação) Programa de Pós-Graduação em Educação. Universidade Federal da Paraíba, João Pessoa, 2009.

THIOLLENT, M. Metodologia da pesquisa-ação. São Paulo: Cortez, 1986. 